\title{
Re-Shaping Social Care Services for Older People in England: Policy Development and the Problem of Achieving 'Good Care'
}

\author{
JANE LEWIS and ANNE WEST \\ Department of Social Policy, London School of Economics and Political Science, Houghton \\ Street, London WC2A 2AE \\ email: J.Lewis@/se.ac.uk; A.West@/se.ac.uk
}

\begin{abstract}
The first part of the paper argues that the care relationship is crucial to securing care quality, which has implications for the way in which quality is achieved and measured. However, for more than twenty years, governments have emphasised the part that increasing market competition and, more recently, user choice of services can play in driving up the quality of care. The second part of the paper analyses the development of social care services for older people, from the reform of 1990 to the changes following the general election of 2010. The paper goes on to examine whether competition and choice are in any case enough to result in 'good care', given the evidence of limitations both in the amount of choice available and in how far older people are able or willing to choose. It is argued that if 'good care' depends disproportionately on the quality of the care relationship, then more attention should be paid to the care workforce, which has received relatively little comment in recent government documents.
\end{abstract}

\section{Introduction}

The longstanding problems of the social care system have become all the more acute in recent years in face of what has been recognised as one of the main internal challenges to modern welfare states: demographic change. While the years of healthy life expectancy are increasing, the expected rise in the population of the over eighty-fives is forecasted to bring with it an increase in the numbers of people with dementia and other disabilities. The UK Home Care Association (UKHCA) has reported a 24 per cent increase in people requiring intensive home care between 2005 and 2010 (UKHCA, 2012a), while as many as 80 per cent of care home residents suffer from dementia (Quince, 2013). In addition, fewer informal carers are likely to be available, particularly daughters, as a result of higher female employment rates and more childlessness. When austerity funding settlements and pressures on health services are added to the mix, the problem of formal social care provision becomes more pressing still. 
Social care has often been regarded as the 'Cinderella' service of the British post-war welfare state, operating on a means-tested basis using mainly the non-ringfenced Revenue Support Grant made by central to local government, with considerable differences between local authorities (LAs) about decisions on funding applicants. While social care has always been a mixed economy of provision, the independent (especially the private) sector has become overwhelmingly dominant: only 5 per cent of home-care services were delivered by the independent sector in 1993, but by 2011 this figure had risen to 81 per cent (UKHCA, 2012b), and 92 per cent of care homes registered with the regulator (the Care Quality Commission) were in the independent sector by 2009 (Eborall et al., 2010). LAs have increasingly been called upon to 'shape' and to 'manage' the market, rather than directly to provide services, and must continue to ration the money available by imposing eligibility criteria on would-be service users and setting the fees paid to independent providers.

For more than twenty years, governments have accepted the idea that increasing market competition and, more recently, enabling user choice of services will result in more personally tailored services and 'drive up' the quality of care, given that people cannot be forced or incentivised to care. Yet major recent scandals have exposed a shameful absence of 'care' - including neglect of nutrition, hydration, pressure sores, lack of dignity and both unkind and illtreatment - in domiciliary care and care homes (EHRC, 2011; Commission on Dignity and Care, 2012; see also CQC, 2012). However, 'good care' is notoriously hard to define, measure and secure. The most important dimension of care that tends to be passed over in recent government approaches to policy is the nature of the interaction between service user and care worker: the care relationship. Recent policies of both the Labour and Conservative-Liberal Democrat Coalition Governments have sought to tilt the balance of attention and concern towards the service user as the consumer of social care, but as Fixsen et al. (2005: 46) have observed: '[i]n human services, practitioners are the intervention' (their emphasis), which in turn makes issues such as the regulation and improvement in working conditions and pay of care workers major factors in achieving highquality care.

The first part of the paper explores the issue of what constitutes good care, arguing that care quality inheres in the care relationship whatever the care setting - in the home or in institutions - which means that the welfare of both user and carer are crucial to it. The second section examines the development of the government's competition and choice model, which, together with changes in the state's approach to regulation, carries assumptions about how to achieve care quality. The third part of the paper explores the extent to which the promise of empowering service users as consumers in the social care market is likely to be realised, and how far this captures what needs to be done to ensure good care. 
The fourth section suggests that given the centrality of the 'care relationship' to good care, more attention needs to be paid to the position of care workers.

\section{What is 'good care'?}

More than three decades ago, Roy Parker (1981) suggested substituting the word 'tending' for the work involved in caring for someone. The wave of 1980 os feminist literature focused on mainly informal, unpaid carework and more on the carer than on the person cared for, but also questioned the idea that care work could ever be 'reduced' to tending, or, later, to 'tasks' such as bathing, feeding and toileting, that could be commodified (Ungerson, 1983, 1987; Lewis and Meredith, 1989). 'Caring about' the person-cared-for was conceptualised as an integral part of carework, involving compassion and kindness, which cannot be legislated for or commodified. Most importantly, these authors emphasised that 'the care relationship' was crucial to the experience of care (see also Qureshi and Walker, 1988). This point was also emphasised by Donabedian (1988) in his study of the quality of medical care (in the US), and has remained central to the literature considering the problem of care quality in the formal, paid sphere. Thus, in their article on measuring quality, Malley and Fernandez (2010: 561) have acknowledged 'the central role of the carer-service user relationship'.

However, this makes it difficult to assess and measure good care because it becomes impossible to confine measures of quality to the efficient and able performance of tasks. The rationality of care is other oriented, defying bureaucratic rationality (Waerness, 1987), and making it difficult to deliver on a 'time and task' basis in accordance with the tenets of new public management. Commissioning on the basis of 'time and task' has excluded the costs of the emotional labour needed to build a relationship with the user. However, work on the ethic of care has stressed the importance of the moral qualities of the care worker in terms of attentiveness, responsibility and responsiveness as well as competence (Tronto, 1993).

Over the last decade, the policy focus in respect of care quality has moved strongly towards outcomes and measures related to the objectives of the user, rather than structural (input) measures, such as the institutional environment or staffing levels, or process measures, which tend to rely on inspection. But outcomes are difficult to measure (Knapp et al., 2001) and people differ considerably in terms of their priorities (Francis and Netten, 2004). Day and Klein (1987: 386) stated the problem vividly a quarter of a century ago in their review of care quality for older people in institutions:

For those among the elderly whose desired outcome may be a quick and easy passage to the grave how do we measure its achievement? For those suffering from Alzheimer's disease how do we assess quality of life? For those who value their own privacy how do we devise measures which do not confuse quality of life with an intrusive insistence on social activity? 
Process measures have the best chance of saying something about the nature of the important care relationship. As Day and Klein (ibid.) observed: 'In the case of care for the elderly quality resides largely in process - that is, the way in which patients are treated.' Similarly Ebrahim et al. (1993: 202) observed that 'the processes of care are of the greatest importance in determining whether a home is good or bad ... It is the staff who make or break residents' lives.' Thus, it is highly unlikely that focusing on only one of three commonly accepted approaches to quality - outcomes (rather than structure or process) - will capture the crucial interaction between user and carer on which good care depends.

More of a focus on the care relationship means that it is impossible to leave the carer out of the analysis. As Himmelweit (1999: 29) has commented: 'the process of caring is itself the development of the relationship'. Focusing entirely on either the carer or the care user is problematic; consideration of the care relationship leads to an emphasis on interdependence (Barnes, 2012). The current policy aim is to empower service users and increase their independence, but anyone requiring help with personal care tasks is dependent on the quality of that help in terms of technical competence and interpersonal qualities (Donabedian, 1988).

As the next sections show, the thinking behind social care policy for the past thirty years has been first that provider competition will drive quality, and second that empowering users as consumers in the social care marketplace will ensure they get the kind of care that they want. But if the care relationship is to be taken seriously, the position of care workers also needs to be considered. The technical and interpersonal components of carework have implications for the training and regulation of the workforce, staffing levels and the time care workers have to spend with service users. To take the issue of poor nutritional status among older people in institutions, the 'red tray' system has been promoted as a solution, by which a person requiring help to eat is given meals on red trays (e.g., Age UK, 2010). This may indeed ensure that these residents are fed, but it does not address the nature of the interaction between carer and the older person - the process of care - and does not ensure that the resident will be helped to eat with patience, skill and kindness. Indeed, it may be that a resident's nutritional status is good, thus contributing to a good outcome measure, but that the care is experienced as bad.

\section{Reforming the social care system: policy development in England The legacy of the 1990 social care reform}

The first reform of social care explicitly to promote market competition was that of 1990, implemented in 1993, the earliest in Western Europe (Pavolini and Ranci, 2008). This was brought about largely by the unintended consequences of a change made to the social security regulations in 1983, which tilted the balance of provision firmly towards institutional care by allowing an older person to enter 
a private residential or nursing home and claim the costs from the state without undergoing an assessment. Public spending on private residential and nursing homes spiralled from $\mathfrak{E}_{2}$ om in 1979 to $\mathfrak{E} 459 \mathrm{~m}$ in 1986 (Lewis and Glennerster, 1996; see also Means et al., 2002). The 1990 legislative changes sought to remedy this social security fiasco and limit public expenditure, while also seeking to stop the large numbers of privately run care homes that had been established from going bankrupt.

The broad effects of the major changes of the early 1990s were still clearly visible more than a decade later and are important for understanding the approach taken to more recent attempts at reform (Brennan et al., 2012 stress the importance of political context and policy history).

First, the changes sought to encourage the development of a quasi-market in social care, in which the local authority commissioned services and the independent (increasingly private) sector provided them. Thus, service users were not the purchasers. Second, local authorities were given responsibility for social care, and, faced with increasing numbers of older people wanting social care services, tightened their eligibility criteria, funding only those assessed as being high need/high risk, albeit with considerable variation between authorities as to how this was defined. Third, local authorities largely abandoned spot contracts to meet the needs of a particular older person in favour of block contracts for 'set list' services, which worked out cheaper. These made it difficult for those acting as care managers (usually social workers) to assess need independently of their knowledge as to which services were actually available, and care management became more about targeting services than assessing need. Fourth, home-care workers were permitted to undertake personal care tasks, and increasingly local authorities commissioned domiciliary care on a 'task and time' basis. This all too often resulted in short visits of thirty minutes or less, which gave too little time to prepare food, help the older person to get up, drink, eat and take medication, as well as to check on the cleanliness of the house. In addition, service users tended to experience a lack of continuity of care (Lewis and Glennerster, 1996).

The Audit Commission (1992) had predicted that the quasi-market would result in greater choice, flexibility, responsiveness, quality and cost effectiveness. However, applying the test as to whether 'Mrs. Smith' would be helped to bed at a time of her choosing, Lewis and Glennerster (1996) concluded that little had changed in respect of the first three of these. But outsourcing social care did save money. By 2009/10 the average unit cost of (usually more specialised) in-house local authority home care was $\mathfrak{E}_{30.85}$ p per hour, whereas the average cost for independent providers was $\mathfrak{E} 15.10 \mathrm{p}$ (UKHCA, 2012a).

\section{Regulatory reform and enabling individual choice, 1997-2010}

In order to address the problems thrown up by the 1990 reforms, Labour pursued a dual strategy of first, more national regulation, and later an effort to 
personalise services by enabling consumer choice in the social care market. In 2003, four 'Fair Access to Services' bands (critical, substantial, medium and low) were introduced for the whole of England in an effort to address the postcode lottery of social care. However, financial cutbacks since 2009/10 have resulted in a large majority of LAs setting their eligibility thresholds at 'substantial'. Also in 2003, increasing concern about the quality of services resulted in Labour introducing National Minimum Standards (NMS) on such matters as the ratio of staff with a National Vocational Qualification (NVQ) level $2^{1}$ to untrained staff, induction training and procedures for the recruitment and selection of staff, as well as for recording the wishes of service users. However, as late as 2010, 21 per cent of domiciliary care providers failed to meet the NMS (Rubery et al., 2011).

Changes after 2005 built on Labour's 'personalisation' agenda for the reform of public services, which sought to address the failings of 'bureau professional control' emanating from the 1990 reform by making care person- rather than task-centred. The changes have been particularly marked in home care, where the service user (rather than the care manager and the local authority) has increasingly been able to act as a consumer and buy services using a 'direct payment' (DP), although money may be taken as a 'personal budget' that continues to be administered by the local authority. But adoption of direct payments was slow prior to the late 2000 s and has remained slow for older people (Fenton, 2011); only 15 per cent of expenditure on home care and direct payments for 2011-12 went to over-sixty-fives in the form of a DP, compared to 57 per cent in respect of the physically disabled, aged eighteen to sixty-five (HSCI, 2013a).

The idea of enabling service users to choose the services they wanted - to 'take control' - was originally promoted by the disability rights movement. Personal budgets taken as direct payments were piloted by In Control, an influential disabilities organisation. For the disability rights movement, DPs were (i) a matter of social justice marking the transition from a professional gift model to a citizen entitlement model, (ii) consumerist and democratic and (iii) were suitable for all service users (Duffy, 2010; Needham, 2011; Glasby and Littlechild, 2009).

The Audit Commission (2006) reiterated its position on choice: more choice would result in higher quality, together with increased control and greater satisfaction on the part of users. However, LAs have continued to determine how much money can be spent and to set the rates paid to independent providers. Thus, while it has been increasingly expected that older people will play a key role in assessing their needs and commissioning services to meet them, regardless of whether they are in receipt of a DP, the social care market has remained far from being a conventional market.

Labour accepted the idea that personal budgets entailed the development of a more diverse market of services from which service users could choose. 
The Conservative Party also endorsed personalisation and with it the further development of the social care market. Enabling choice served those wishing to prioritise market building as well as those interested mainly in promoting autonomy, rights and citizenship. Both political parties were convinced by evidence that personal budgets could improve services and yet be cost neutral. While the large-scale evaluation of Labour's pilot programme reported no sign of a cost effectiveness advantage for elderly budget holders (Glendinning et al., 2008: 111), no study reported increased costs.

Personalisation and personal budgets were thus envisaged as tackling many of the problems arising from the 1990 reform, particularly in terms of abolishing 'one-size-fits-all', 'set list' services and allowing users to choose services, including those intended to meet lower levels of need.

\section{Post-2010: towards a smaller role for the central state}

After the 2010 election, the Coalition Government endorsed personalisation and personal budgets, promising legislation to provide an entitlement to personal budgets and to 'rule out "crude contracting by the minute"' (HM Government, 2012a: 10 and 12). However, while personal budgets were conceived at a time of plenty, they are being implemented during a period of austerity and swinging cuts to LAs' Revenue Support Grant. Over the three years since the introduction of the austerity programme, $\mathfrak{E} 2.68$ bn savings will have been made in adult social care, 20 per cent of net spending (ADASS, 2013). Nevertheless, the Coalition Government has denied the existence of a funding gap (and unmet need) (House of Commons, 2012a: paras. 60 and 61), and has also stated that there is no reason for LAs to tighten their current eligibility thresholds (HM Government, 2012a: 32).

The Coalition Government has also taken forward an outcomes approach to quality, with performance measures relying on outcomes for the service user. Thus, one of the eight indicators of 'social care-related quality of life' includes 'the way people are treated', but this, like other indicators of the overarching quality of life measure, relies on survey data rather than inspection and observation of the care process $(\mathrm{DH}, 2011 \mathrm{a})$. However, there may be many reasons why care users may not be able or willing to fill in surveys honestly or at all. The trend towards the use of outcome indicators for quality monitoring is more advanced in England than in many EU member states (DG Employment, Social Affairs and Equal Opportunities, 2010; Dandi et al., 2012).

The National Minimum Standards established by Labour were abandoned and the Care Quality Commission (CQC) stopped the system of quality ratings for care homes in June 2010. Since its inception in 2009, the CQC has operated an essentially risk-based approach to ensuring quality, measuring performance against 'essential minimum standards' (House of Commons, 2012b). Nevertheless, on the basis of 13,000 inspections in 2011/12, the CQC documented 
substantial failings (particularly in nursing homes) in regard to standards on nutrition and respect for dignity, having enough staff on duty to provide good services and on providers' assessment and monitoring of the quality of care (CQC, 2012, 2013a). However, Amanda Sherlock, CQC operations director, told the Health Select Committee's annual accountability hearing that 'the public have to tell us' about inadequate staffing (House of Commons, 2011: Q. 226, ital. added).

The Coalition Government has championed more autonomy for care workers, arguing that the vast majority 'do not strive to provide excellent care because they fear regulatory action if they do wrong or because they are told to do things properly. They do so because they are caring people, who are well trained and well motivated' (HM Government, 2011: 4). The vast majority of care workers are indeed likely to fit much of this description (particularly the first part), but the recent reports on care scandals (see Introduction) show that some do not. Nevertheless, the 2012 White Paper on social care states clearly that quality is 'first and foremost the responsibility of providers' (HM Government, 2012a: 37), and after that of service users and their families.

It is assumed that user choice in a diverse social care market will drive quality improvement. This relies on individual purchasing decisions cumulatively creating a 'trickle-up' effect on service development and quality, which will in turn impact on market supply (Stevens et al., 2011). But, as the next section shows, there may be significant barriers to user choice.

\section{Is enabling choice in the social care market enough to secure good care?}

There is now a substantial body of evidence that casts doubt over the degree to which there will be choice of service, and how far older people want to choose. A report compiled by Deloitte and Touche (2008) on long-term care markets pointed out that the inefficiencies and inequities of the social care market mean that care services are not always available to those who need them. It does not help that information about services tends to be poor (Baxter and Glendinning, 2011), but above all choice remains subject to financial constraints and the extent to which (often vulnerable) older people do not want or are unable to exercise choice, often prioritising instead the way in which the service is delivered (ADASS, 2012).

Choice is constrained by money in a number of different ways. The limits placed by central government on local authority budgets since 2010 have resulted in further rationing. The vast majority of LAs (79 per cent) have sought to freeze or reduce the fees paid to independent providers (ADASS, 2012). In care homes, this is likely both to make more homes more dependent on cross-subsidy from self-funding residents and to threaten staffing levels. Not surprisingly (but in 
contradiction to the Coalition Government's exhortations) short home visits have also increased; 73 per cent of visits made by the 739 providers responding to a UKHCA survey were 30 minutes or shorter and 34 per cent of providers feared that this put the dignity of the user at risk (UKHCA, 2012a). The meaning of short home visits was made clear by a service user in an independent report to the Cabinet Office on barriers to choice:

Old age comes out of the blue, and one is horrified that one experiences changes in body and person so quickly ... When they told me that, if I couldn't wash in 45 minutes, they would only offer me a strip wash, I was appalled and frightened. (Boyle, 2013: 42)

UNISON's 2012 survey of home-care workers emphasised the extent to which carers were having to rush their visits: 'the all important "meet and greet" and chat to establish if there are any problems falls by the wayside' (UNISON, 2012: 6). It may be that users will increasingly face a choice between deteriorating, rather than improving, services.

Eligibility thresholds for service users are likely to continue to be tightened. For 2012/13, 83 per cent of LAs set their eligibility thresholds at 'substantial' and 2 per cent at 'critical'(CQC, 2012). In home care, if the LA only meets substantial or critical needs, then the scope for creative 'support planning' is inevitably small. In addition, the unit of resource for older people receiving direct payments was only $\mathfrak{E}_{155}$ per week in 2011-12, compared to $\mathfrak{E}_{23} 6$ per week for those under sixty-five with physical disabilities; while the figures for home care were $\mathfrak{E}_{177}$ for older people compared to $\mathfrak{L}_{2 \mathrm{O} 2}$ for people with physical disabilities (HSCI, 2013b). The amount allocated to older people for home care is often only enough to cover personal care delivered by a personal assistant (PA) (SCIE, 2011), rendering any desire to choose to spend the money on something else - gardening, swimming or a dog walker, for instance - stillborn.

It is unlikely that resource allocation to users will become more generous. In April 2013, 47 per cent of 145 (of 152) top tier social services authorities reported that increasing personalisation was highly important as an aid to saving resources (ADASS, 2013). Indeed, the 2012 Health Select Committee expressed the fear that as a growing number of people are allocated personal budgets and have their 'care needs quantified and converted into a sum of money through a resource allocation system' it might be that 'people's needs could be assessed less personally and could develop into an entitlement-based system which awards them a specific cash amount under a process more akin to social security than social care' (House of Commons, 2012a: para. 79). This is a reference back to what happened during the 1980s, but such a fear runs counter to the hope of In Control that personal budgets would signal a shift to a citizen entitlement model.

Choice is also supposed to give service users control over their care, but in regard to home care, it is recognised that many service users still want and need help in carrying out self-assessment and in identifying the outcomes they 
want to achieve (Orellana, 2010). Much therefore depends on the skill levels of those carrying out assessments and negotiating budgets. However, the Audit Commission (2012) proposed that LAs save money by reviewing the skill mix of staff carrying out assessments.

There remains evidence that not all service users want or are able to exercise choice or take control, something clearly signalled by Baldock and Ungerson's (1994) work on stroke patients and their carers twenty years ago. As Eika (2009) has pointed out and as the National Audit Office (NAO) has acknowledged, older people have all too often only 'limited consumer sovereignty' (NAO, 2011). They are often vulnerable - for example, they are likely to enter a care home at a time of crisis when they are not in a position to make considered choices - and an increasing proportion suffer from dementia. Nor are they likely subsequently to choose to exit the home, whether because of a desire to avoid disruption, undue deference or incapacity (Wilberforce et al., 2011). The findings of a survey conducted for the NAO in 2011 (NAO, 2011) reinforced those of Glendinning et al. (2008), that is, that older people have more anxiety about personal budgets and were less positive about them than other groups. In a study that stressed the part that professionals could play in dissuading older people from becoming holders of direct payments, a social worker was quoted as saying that older people in crisis want things to be sorted out for them and 'don't want to be lumbered with more responsibility' (Ellis, 2007: 413). This may actually be an accurate assessment of the situation rather than the simple denial of user control.

Older people have been shown to be particularly anxious about direct payments and about taking responsibility for employing a personal assistant (Glendinning et al., 2008; IFF, 2008; NAO, 2011). Both the Labour and Coalition Governments have referred to the importance of allowing service users to make choices and take risks (e.g., SCIE, 2010), although as Needham (2011) has noted, choice to go to a football match rather than a day centre may threaten the viability of the centre and thus thwart the choice of those who prefer the day centre. However, taking the risk to spend part of a direct payment on going to a football match is qualitatively different from using the payment to employ a PA, who may not be previously known to the service user, for whom there is still no system of registration (despite one being promised as long ago as 2006), ${ }^{2}$ and for whose employment conditions the older person will be responsible. Glendinning (2012) has called attention to the increasing fragmentation and lack of regulation of the home-care workforce. In many cases, it will be difficult for older people with no informal kin support to take on the role of employers. ${ }^{3}$ Assuming both the legal responsibilities and the transaction costs associated with a particular service amounts to privatisation to the individual service user (Hacker, 2006). Indeed, the Coalition Government has stated firmly that 'the emphasis should be on employers of unregulated workers to take responsibility for the quality of services provided' (HM Government, 2011: 16). These responsibilities may be 
welcomed by some service users - for example, the young, physically disabled person who finds it both easy and preferable to use the internet to hire a student willing to work part-time as a carer - but not by frail and forgetful older people who are unable to take advantage of new technologies and lack the confidence to become employers.

Nevertheless, a large majority of service users have expressed satisfaction with personal assistants, especially if they are previously known to the service user. PAs tend to provide greater continuity of care and may be expected to work closely to the service user's specification. But it is too early to say whether service users are able to get the care they want as their dependency increases. Residents in care homes may have had very little by way of choice, or choice between mediocre establishments with poorly developed person-centred care. The idea that major improvement will be driven by market failure and closure of a poor-quality facility is far from comforting for frail elderly people. There is a profound disconnect between the need for continuity of competent, attentive and responsive care as a necessary building block for a good care relationship on the one hand, and the need to experience bad care in order to drive quality improvement in the market on the other.

Older people are not necessarily able to access the services they want, or to 'take control' of their own care arrangements. Nor will competition and choice necessarily drive quality in a user-friendly way. Regardless of whether they are able and willing actively to make choices, users must rely on the quality of care and/or support offered by a care worker. Yet the conditions, pay, competence and regulation of care workers are issues that have been conspicuously absent from recent policy documents; the 2012 White Paper on social care made little reference to the care workforce other than to emphasise the importance of leadership (HM Government, 2012a: 38).

\section{The care relationship and the care workforce}

The recent reforms of social care have sought to tilt the balance of power and control between service users and care workers/providers in favour of users. However, the balance of the relationship between front line care workers and older people is delicate in both domiciliary and institutional settings. If good care hinges on the quality of the care relationship, then the position of the care workforce is important. As Rubery and Urwin (2010: 122) have argued: 'quality cannot be disentangled from this human interaction [between user and carer] and improvement strategies have to engage with the attitudes, skills and commitments of the people providing the care'. Research on nursing homes in California and Pensylvania showed the connection between poor-quality jobs and poor-quality care, which are all too often treated as separate issues (Eaton, 2000; see also UNISON, 2012 on home-care workers). Yet downward pressure on LA budgets is 
likely to penalise good-quality providers who invest in staff training, pay decent wages and ensure appropriate staffing levels, by focusing commissioning more on price than quality (UKHCA, 2012a), for example, via renewed pressure to keep visits short.

While the 2012 Draft Care and Support Bill acknowledged the link between quality of service and 'a caring, skilled and valued workforce' (HM Government, 2012b: para. 3.2), it did not name an agency to take responsibility for training in the field of social care; it is likely that staff training will continue to be seen as the responsibility of commissioners (including users drawing direct payments) and providers. Furthermore, there is a tendency on the part of policymakers to think that carework can be done by anyone. Thus, the Centre for Workforce Intelligence (CWI, 2011) suggested that young and unemployed people should be encouraged to enter care work, despite evidence indicating that better quality care is associated with older, more experienced workers (Netten et al., 2007). In their article on measuring quality Malley and Fernandez (2010) argued that the 'technical' skill component of care is, in general, low, evidenced by the way in which informal, untrained carers usually do a good job. However, this does not imply that anyone can do the job well: the interpersonal relationship is a 'vitally important element' (Donabedian, 1988: 1744) and it may be that informal carers, such as family and friends, have the time to proceed slowly and to learn how best to manage probably the only person they care for.

Employers, whether providers or direct payment holders, have been shown to attach more importance to personality, patience and emotional connection than to skills when hiring care workers (Wild et al., 2010; Walsh and Shutes, 2013). While this may seem to be in line with an emphasis on the importance of relationship, service users may also need more skilled help if their condition deteriorates. The first quality standard for dementia issued by the National Institute for Health and Clinical Excellence calls for staff working with care users suffering from dementia to have appropriate training, but leaves the implementation of this to commissioners and providers. UNISON's survey of home-carers found that 41 per cent were not given specialist training to deal with their clients' specific medical needs, such as dementia and stroke (UNISON, 2012). While the old NVQ courses may well not have been the most appropriate qualifications, ${ }^{4}$ a 2010 report found that employers generally approved of the NMS training standards introduced by Labour, 'seeing them as having increased the proportion of qualified staff in the workforce, which would otherwise not have happened, and as a significant lever for quality improvement' (Eborall et al., 2010: 152).

Surveys of PAs have reported that a significant minority felt that they needed training, especially in administering medication, moving and handling and personal care (IFF, 2008; PFA, 2011). As the CQC noted on the basis of its recent home-care inspections, 'the needs of people aged 65 and over who receive care in their own home are becoming more complex, and in many cases include 
the provision of care for people with dementia' (CQC, 2013b: 7). Indeed, the UK Homecare Association has questioned the promotion of 'a cash payment system for the engagement of untrained, unqualified, unsupported and unregulated personal assistants' (House of Commons, 2010: paras. 347 and 363).

It seems that the Coalition Government supports only 'creative' (and probably cheaper) solutions to the problem of staff training such as e-learning, which it anticipates will be taken forward 'at the most appropriate level within individual communities'; how is not specified ( $\mathrm{DH}, 2011 \mathrm{~b}: 36$ ). In the case of personal assistants, to insist on any particular level of training is also felt to fly in the face of the service user's right to employ whomever s/he pleases (House of Commons, 2010: para. 367). However, as the Pearson Report (Commission on Dignity in Care, 2012: 13) on care homes pointed out, 'staff who are denied the right to training and development and who do not feel valued ... are likely to deliver poor care'.

There is no clear career pathway for care workers and the work is poorly paid (HM Government, 2012c). Lord Sutherland, who chaired the 1999 Royal Commission on Long-Term Care, told the 2010 Health Select Committee that care home workers must be either " "altruistic or desperate" ' (House of Commons, 2010: para. 148). In fact, a substantial minority of care workers today are migrants, 8 per cent in the UK as a whole, rising to 50 per cent in London (Cangiano et al., 2009). Rubery et al.'s (2011) survey found that pay levels clustered in a band no more than $\mathfrak{E}_{1}$ above the national minimum wage, nor did higher qualifications, overtime, or unsocial hours attract very much by way of extra pay. UNISON's survey of home-carers found that 58 per cent were not paid for travel time (UNISON, 2012). Indeed, surveys have found considerable dissatisfaction about pay among PAs (IFF, 2008, Rubery et al., 2011).

It is unsurprising that there are also problems of retention, which are particularly severe for the independent sector, where staff turnover averaged 24 per cent a year for care homes and 31 per cent for domiciliary care (Rubery et al., 2011), with implications for the continuity and quality of care. The Coalition Government has stated that 'where employers are fully engaged with the local community, exercising choice and control and encouraging PAs to undergo training they are more likely to retain staff ( $\mathrm{DH}, 2011 \mathrm{~b}$ : 20), which makes the conditions of the PA depend on the continued wellbeing and benign intentions of the older person. Care has to be a personal relationship, but it is not impossible to see the 'situation' of the PA in England as resembling that of a domestic servant, as much as, or more than that of a skilled, autonomous worker.

The central place occupied by the 'care relationship' in determining the quality of care and the changing needs of those using social care services over time demand that more attention be paid to the characteristics and conditions of the social care workforce. It is already likely that several different types of care worker are needed. For example, Moriarty (2008) raised the idea that hybrid 
health and social care domiciliary care workers might be needed, and a report on adult care in the north east of England (PFA, 2011) proposed four levels of home-care workers, the top grade being a specialist PA with advanced care and nursing skills. Similarly, a study of institutional care has advocated the need for different grades of worker (Wild et al., 2010). This kind of development requires central government to undertake workforce planning and to revisit the issues of workforce training and regulation.

\section{Conclusion}

The assumption of recent governments has been and continues to be that competition and choice will drive up quality, with increasingly independent service users acting as consumers in the diverse social care market, making it possible to look to employers (including those service users employing PAs) to secure quality. Government in its turn feels justified in paying less attention in terms of planning, regulation and training to the care workforce. But the social care market can work against some key dimensions of quality. Most importantly, time to care, which is crucial to building a good care relationship, tends not to be costed under the time and task model that dominates commissioning. Continuity of care is also threatened because poor pay and conditions of work lead to high staff turnover, and because quality can be secured in the last instance only by poor-quality providers being forced to exit the market. The social care market is unequal and inefficient, and the social care system is being subjected to severe cost containment due to the Coalition's austerity programme, which is driving down the prices paid to providers and thus threatens to reduce investment in the social care workforce. Service users may increasingly face choices between services that are decreasing in quality.

If services are to be provided mainly by the private sector, the problems arising from the 1990 reform suggest that it may indeed be likely that a better service will result from direct purchasing by the citizen/consumer rather than by local authorities' block contracts. However, there are also many barriers to choice. Older people have very different needs and very different capacities and opportunities to exercise choice. In any case, the quality and desirability of a service, tends to be an 'experience good' (NAO, 2011): it has to be tried in order to determine whether it is satisfactory, but, once tried, it may be hard for the older person to exit, especially from a care home to which most are admitted only for the very last years of their lives. Leaving quality to market mechanisms poses problems for service users, many of whom are vulnerable. Nor are they necessarily able to access information, vital for the market to function and for authentic choices to be made, especially if they are cognitively impaired. Indeed, both front line carers and the people they care for are likely to be women and to be poor, with little leverage in the social care market. 
The recent investigation of poor quality in home care by the Equality and Human Rights Commission (EHRC, 2011) suggested that the solution lies in ensuring that the human rights of older people are respected by all involved, while the Pearson Report on poor-quality institutional care called for carers to respect the dignity of the cared for. However, it is noteworthy that Pearson rejected the possibility of setting ratios of trained and untrained care home staff to older residents (Commission on Dignity in Care, 2012). While values are undoubtedly important and while it must surely be crucial to hire care workers who are kind and compassionate, neither of the reports considers the importance of inspecting the care process and the structural regulation that might be necessary to ensure appropriate numbers of workers with particular skills. In a sense, both reports are groping towards the importance of the care relationship, but neither pays sufficient attention to the position of care workers, for whom adequate investment in, and regulation of training, as well as regulation of practices regarding registration, hiring and working conditions are crucial. The 'how' of the solutions suggested by the reports arising from the scandals of poorquality care is rather vague, just as the recent government documents have also tended to will policy ends, without willing the means in terms of either public expenditure or state intervention.

\section{Notes}

1 A lower secondary education qualification.

2 The 2012 Health and Social Care Act proposed only voluntary registration.

3 Responsibilities of those employing PAs include: checking references, producing wage slips, deducting income tax and national insurance contributions, record keeping, ensuring that the PA has an annual leave entitlement, ensuring that the home presents no health or safety dangers, taking out insurance cover and finding out whether the PA has had a Criminal Records Bureau check (http://www.nhs.uk/CarersDirect/guide/practicalsupport/ Pages/Directpayments.aspx, accessed 15 May 2013).

4 NVQs were replaced in January 2011 by new Diplomas and smaller Awards and Certificates for continued professional development within the Qualifications and Credit Framework.

\section{References}

Age UK (2010), Still Hungry to be Heard, London: Age UK.

Association of Directors of Adult Social Services (ADASS) (2012), The Case for Tomorrow: Facing the Beyond, London: ADASS.

Association of Directors of Adult Social Services (ADASS) (2013), Budget Survey, 2013, London: ADASS.

Audit Commission (1992), Community Care: The Cascade of Change, London: HMSO.

Audit Commission (2006), Choosing Well: Analysing the Costs and Benefits of Choice in Local Public Services, London: Audit Commission.

Audit Commission (2012), Reducing the Costs of Assessments and Reviews, London: Audit Commission.

Baldock, J. and Ungerson, C. (1994), Becoming Consumers of Community Care: Households within the Mixed Economy of Care, York: Joseph Rowntree Foundation. 
Barnes, M. (2012), Care in Everyday Life: An Ethic of Care in Practice, Bristol: The Policy Press.

Baxter, K. and Glendinning, C. (2011), 'Making choices about support services: disabled adults' and older people's use of information', Health and Social Care in the Community, 19: 3, 272-9.

Boyle, D. (2013), The Barriers to Choice Review: How Are People Using Choice in Public Services? London: Cabinet Office.

Brennan, D., Cass, B., Himmelweit, S. and Szebehely, M. (2012), 'The marketisation of care: rationales and consequences in Nordic and liberal care regimes', Journal of European Social Policy, 22: 4, 377-91.

Cangiano, A., Shutes, I., Spencer, S. and Leeson, G. (2009), Migrant Care Workers in Ageing Societies, Oxford: COMPAS, University of Oxford.

Care Quality Commission (CQC) (2012), The State of Health Care and Adult Social Care in England in 2011/12, HC 763, London: The Stationery Office, http://www.cqc.org.uk/sites/ default/files/media/documents/cqc_soc_201112_final_tag.pdf.

Care Quality Commission (CQC) (2013a), Time to Listen, Dignity and Nutrition Inspection Programme, National Overview, London: CQC.

Care Quality Commission (CQC) (2013b), Not Just a Number, Home Care Inspection Programme, National Overview, London: CQC.

Centre for Workforce Intelligence (CWI) (2011), Workforce Risks and Opportunities: Adult Social Care, London: CWI.

Commission on Dignity in Care (2012), Delivering Dignity, London: LGA, NHS Confederation and Age UK.

Dandi, R., Casanova, G., Lillini, R., Volpe, M., de Belvis, A. G., Avolio, M. and Pelone, F. (2012), Long-Term Care Quality Assurance Policies in European Countries, 7th Framework Programme Report no. 111, Brussels: ENEPRI.

Day, P. and Klein, R. (1987), 'Quality of institutional care and the elderly: policy issues and options', British Medical Journal, 294: 384-7.

Deloitte \& Touche LLP (2008), Mapping Care of Older People, London: Deloitte \& Touche LLP.

Department of Health (DH) (2011a), Transparency in Outcomes: A Framework for Quality in Adult Social Care, London: DH.

Department of Health (DH) (2011b), Working for Personalised Care: A Framework for Supporting Personal Assistants, London: DH.

DG Employment, Social Affairs and Equal Opportunities (2010), Transnational Home Care Quality Indicators, Brussels: European Commission.

Donabedian, A. (1988), 'The quality of care: how can it be assessed?', Journal of the American Medical Association, 260: 12, 1743-8.

Duffy, S. (2010), The Future of Personalisation: Implications for Welfare Reform, London: Centre for Welfare Reform.

Eaton, A. C. (2000), 'Beyond "unloving care": linking human resource management and patient care quality in nursing homes', International Journal of Human Resource Management,11: 3, 591-616.

Eborall, C., Fenton, W. and Woodrow, S. (2010), The State of the Adult Social Care Workforce in England, 2010, London: Skills for Care.

Ebrahim, S., Wallis, C., Brittis, S., Harwood, R. and Graham, N. (1993), 'Long term care for elderly people', Quality in Health Care, 2: 198-203.

Eika, K. H. (2009), 'The challenge of obtaining quality care: limited consumer sovereignty in human services', Feminist Economics, 15: 1, 113-37.

Ellis, K. (2007), 'Direct payments and social work practice: the significance of "street-level bureaucracy" in determining eligibility', British Journal of Social Work, 37: 3, 405-22.

Equality and Human Rights Commission (EHRC) (2011), Close to Home: An Inquiry into Older People and Human Rights in Home Care, London: EHRC.

Fenton, W. (2011), The Size and Structure of the Adult Social Care Sector and Workforce in England, 2011, London: Skills for Care. 
Fixsen, D. L., Naoom, S. F., Blase, K. A., Friedman, R. M. and Wallace, F. (2005), Implementation Research: A Synthesis of the Literature, Tampa, FL: University of South Florida.

Francis, J. and Netten, A. (2004), 'Raising the quality of home care: a study of service users' views', Social Policy and Administration, 38: 3, 290-305.

Glasby, J. and Littlechild, R. (2009), Direct Payments and Personal Budgets: Putting Personalisation into Practice, Bristol: Policy Press.

Glendinning, C. (2012), 'Home care in England: markets in the context of under-funding', Health and Social Care, 20: 3, 292-9.

Glendinning, C., Challis, D., Fernandex, J.-L. et al. (2008), The National Evaluation of the Individual Budgets Pilot Programme, York: Social Policy Research Unit, University of York.

Hacker, J. (2006), The Great Risk Shift, Oxford: Oxford University Press.

Health and Social Care Information Centre (HSCI) (2013a), Personal Social Services: Expenditure and Unit Costs England, 2011-12, Final Results: National Detailed Expenditure, https://catalogue.ic.nhs.uk/publications/social-care/expenditure/pss-exp-eng-11-12fin/pss-exp-eng-11-12-fin-nat-det-exp.xls (accessed 8 May 2013).

Health and Social Care Information Centre (HSCI) (2013b), Personal Social Services: Expenditure and Unit Costs England, 2011-12: Final Release, Table 6.1, http://www.hscic.gov.uk/ catalogue/PUBo9820 (accessed 8 May 2013).

Himmelweit, S. (1999), 'Caring labor', ANNALS of the American Academy of Political and Social Science, 561: 27-38.

HM Government (2011), Enabling Excellence: Autonomy and Accountability for Healthcare Workers, Social Workers and Social Care Workers, Cm 8008, London: The Stationery Office.

HM Government (2012a), Caring for our Future: Reforming Care and Support, Cm 8378, London: The Stationery Office.

HM Government (2012b), Draft Care and Support Bill, Cm 8386, London: The Stationery Office.

HM Government (2012c), National Minimum Wage, Report of the Low Pay Commission, Cm 8302, London: The Stationery Office.

House of Commons (2010), Social Care, Third Report of Session 2009-10, Health Committee, HC 22-I, London: The Stationery Office, http://www.publications.parliament.uk/pa/ $\mathrm{cm} 200910 / \mathrm{cmselect} / \mathrm{cmhealth} / 22 / 22$.pdf.

House of Commons (2011), Annual Accountability Hearing with the Care Quality Commission, Ninth Report of Session 2010-12, Health Committee, HC 1430, London: The Stationery Office, http://www.publications.parliament.uk/pa/cm201012/cmselect/ cmhealth/1430/1430.pdf.

House of Commons (2012a), Social Care, Fourteenth Report of Session 2010-12, Select Committee on Health, HC 1583, London: The Stationery Office, http://www.publications. parliament.uk/pa/cm201012/cmselect/cmhealth/1583/1583.pdf.

House of Commons (2012b), The Care Quality Commission: Regulating the Quality and Safety of Health and Adult Social Care, Seventy-Eighth Report of Session 2010-12, Committee of Public Accounts, HC 1779, London: The Stationery Office, http://www.publications. parliament.uk/pa/cm201012/cmselect/cmpubacc/1779/1779.pdf.

IFF Research (2008), Employment Aspects and Workforce Implications of Direct Payments, London: Skills for Care.

Knapp, M., Hardy, B. and Forder, J. (2001), 'Commissioning for quality: ten years of social care markets in England', Journal of Social Policy, 30: 2, 283-306.

Lewis, J. and Glennerster, H. (1996), Implementing the New Community Care, Buckingham: Open University Press.

Lewis, J. and Meredith, B. (1989), Daughters who Care, London: Routledge.

Malley, J. and Fernandez, J.-L. (2010), 'Measuring quality in social care services: theory and practice', Annals of Public and Cooperative Economics, 81: 4, 559-82.

Means, R., Morbey, H. and Smith, R. (2002), From Community Care to Market Care: The Development of Welfare Services for Older People, Bristol: Policy Press.

Moriarty, J. (2008), The Social Care Workforce in the UK Labour Market, London: Social Care Workforce Research Unit, King's College. 
National Audit Office (NAO) (2011), Oversight of User Choice and Provider Competition in Care Markets, Report by the Comptroller and Auditor General, Session 2010-2012, HC 1458, London: The Stationery Office, http://www.nao.org.uk/wp-content/uploads/2011/ 09/10121458.pdf.

Needham, C. (2011), Personalising Public Services: Understanding the Personalisation Narrative, Bristol: Policy Press.

Netten, A., Jones, K. and Sandhu, S. (2007), 'Provider and care workforce influences on quality of home-care services in England', Journal of Aging and Social Policy, 19: 3, 81-97.

Orellana, K. (2010), Personalisation in Practice: Lessons from experience, London: AgeUK.

Parker, R. (1981), 'Tending and social policy', in E. Matilda Goldberg and St. Hatch, A New Look at the Personal Social Services, Discussion Paper 4, London: Policy Studies Institute.

Pavolini, E. and Ranci, C. (2008), 'Restructuring the welfare state: reforms in long-term care in Western European countries', Journal of European Social Policy, 18: 3, 246-59.

Peter Fletcher Associates (PFA) (2011), The Invisible Workforce - Developing Personal Assistants in the Adult Social Care Workforce, Final Report, Haydon Bridge: PFA.

Quince, C. (2013), Low Expectations: Attitudes on Choice, Care and Community for People with Dementia in Care Homes, London: Alzheimer's Society.

Qureshi, H. and Walker, A. (1989), The Caring Relationship: Elderly People and their Families, Basingstoke: Macmillan.

Rubery, J., Hebson, G. and Grimshaw, D. et al. (2011), The Recruitment and Retention of a Care Workforce for Older People, Manchester: European Work and Employment Research Centre, University of Manchester.

Rubery, J. and Urwin, P. (2010), 'Bringing the employer back in: why social care needs a standard employment relationship', Human Resource Management Journal, 21: 2, 122-36.

Skills for Care (2011), Adult Social Care Workforce Recruitment and Retention Strategy, London: Skills for Care.

Social Care Institute for Excellence (SCIE) (2010), Enabling risk, Ensuring Safety: Self-Directed Support and Personal Budgets, Report 36, London: SCIE.

Social Care Institute for Excellence (SCIE) (2011), Personal Budgets Briefing: Learning from the Experiences of Older People and Their Carers, Report 40, London: SCIE.

Stevens, M., Glendinning, C., Jacobs, S., Moran, N., Challis, D., Manthorpe, J., Fernandez, J.-L., Jones, K., Knapp, M., Netten, A. and Wilberforce, M. (2011), 'Assessing the role of increasing choice in English social care services', Journal of Social Policy, 40: 2, 257-74.

Tronto, J. (1993), Moral Boundaries: A Political Argument for an Ethic of Care, New York: Routledge.

UK Homecare Association (UKHCA) (2012a), Care Is Not a Commodity, Commissioning Survey, London: UKHCA.

UK Homecare Association (UKHCA) (2012b), An Overview of the UK Domiciliary Care Sector, London: UKHCA.

Ungerson, C. (1983), 'Why do women care?', in J. Finch and D. Groves (eds.), A Labour of Love: Women, Work and Caring, London: Routledge \& Kegan Paul, pp. 31-40.

Ungerson, C. (1987), Policy is Personal: Sex, Gender and Informal Care, London: Tavistock.

UNISON (2012), Time to Care, A UNISON report into homecare, London: UNISON.

Waerness, K. (1987), 'On the rationality of caring', in A. S. Sassoon (ed.), Women and State, London: Hutchinson, pp. 207-34.

Walsh, K. and Shutes, I. (2013), 'Care relationships, quality of care and migrant workers caring for older people', Ageing and Society, 12: 2, 205-19.

Wilberforce, M., Glendinning, C., Challis, D., Fernandez, J.-L., Jacobs, S., Jones, K., Knapp, M., Manthorpe, J., Moran, N., Netten, A. and Stevens, M. (2011), 'Implementing consumer choice in long-term care: the impact of individual budgets on social care providers in England', Social Policy and Administration, 45: 5, 593-612.

Wild, D., Szczepura, A. and Nelson, S. (2010), Residential Care Home Workforce Development, York: Joseph Rowntree Foundation. 